\title{
Multicentric recurrent parotid pleomorphic adenoma in a child
}

\author{
Mireya Bonet-Loscertales ${ }^{1}$, Miguel Armengot-Carceller ${ }^{2}$, John Gaona-Morales ${ }^{3}$, Jorge Basterra-Alegría ${ }^{4}$ \\ ${ }^{1}$ MD. General and University Hospital. ENT Department. Valencia, Spain \\ ${ }^{2} \mathrm{MD}, \mathrm{PhD}$. General and University Hospital. ENT Department. ENT Professor, Valencia Medical School. Valencia University. \\ Valencia, Spain \\ ${ }^{3}$ MD. General and University Hospital. Pathology Department. Valencia, Spain \\ ${ }^{4} \mathrm{MD}$, PhD. General and University Hospital. ENT Department. ENT Professor, Valencia Medical School. Valencia University. \\ Valencia, Spain
}

Correspondence:

Servicio de ORL,

Hospital General Universitario de Valencia,

Valencia, Spain

caloteca@hotmail.com

Received: $14 / 09 / 2009$

Accepted: 24/12/2009

Bonet-Loscertales M, Armengot-Carceller M, Gaona-Morales J, Basterra-Alegría J. Multicentric recurrent parotid pleomorphic adenoma in a child. Med Oral Patol Oral Cir Bucal. 2010 Sep 1;15 (5):e743-5. http://www.medicinaoral.com/medoralfree01/v15i5/medoralv15i5p743.pdf

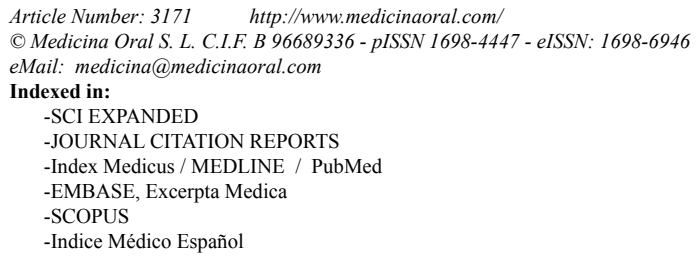

\begin{abstract}
Mixed tumours of the parotid gland are rare in childhood and recurrence of this tumour is infrequent. Some authors report a higher rate of recurrence with some histological subtypes, like hypocellular variant. Female sex and young age at initial treatment are also risk factor for recurrence. Also the first surgical treatment, tumour enucleation or parotidectomy, has been implicated as a cause for recurrence. We present a case of a multicentric doubly recurrent parotid pleomorphic adenoma, 7 and 14 years after tumour enucleation, in a 9-year-old child. All the nodules resected showed the hypocellular variant of pleomorphic adenoma. We consider the relationships between the choice of treatment, the histologic subtypes of pleomorphic adenomas and multifocal tumours and recurrence. In this case, we believe the recurrence was related to surgical enucleation previously performed and the hypocellular histological subtype. We conclude that tumour enucleation is a risk factor for recurrence and total parotidectomy is the treatment of choice for pleomorphic parotid adenoma also in childhood.
\end{abstract}

Key words: Hypocellular pleomorphic adenoma, mixed tumours, multifocal, recurrences, total parotidectomy, enuction.

\section{Introduction}

Parotid tumours are rare in children, and pleomorphic adenoma is the most frequent of such tumours $(1,2)$. Mixed tumours of the parotid gland recur at a rate of $3.4 \%$ after 5 years and $6.8 \%$ after 10 years, with a range of $1-50 \%$. Some authors report a higher rate of recurrence with some histological subtypes, like the hypocellular variant (mucoid) (3). Female sex and young age at initial treatment are also risk factors for recurrence (4). Treatment of these tumours is total parotidectomy, which has a very low rate of local recurrence. By contrast, the local recurrence rate can reach $50 \%$ in patients treated with tumour enucleation because fragments of the capsule are not removed during the surgery. If the tumour is broken during surgery, multicentric recurrence can occur. The risk of facial lesions is higher in recurrence surgery. 
This study discusses a case of doubly recurrent multifocal pleomorphic adenoma that happened 7 and 14 years after tumour enucleation in a 9-year-old child.

\section{Case report}

A 16-year-old woman came to our department with a left parotid tumour that she had had for 2 years. Previous parotid pleomorphic tumour enucleation surgery was performed 7 years earlier in another hospital. The tumour was located in the same place. Clinical examination disclosed three nodules in the left parotid region.

The patient underwent surgery and the three nodules were resected. On histological examination all three nodules consisted of ductal epithelial and myoepithelial elements intermingled with a stromal component. The diagnosis in the three nodules was pleomorphic adenoma.

Seven years later, the patient returned to our Department for follow-up. On clinical examination, several nodules were felt in the parotid area. Cervical computed tomography revealed several small hypodense nodules with fibrous tracts (Fig. 1). The patient underwent further resection of all of the nodules.

The gross study revealed ten nodules of different sizes, with "chondroid" features, surrounded by fatty and fibrous tissue. Microscopically, all ten nodules contained epithelial, myoepithelial, and stromal components to varying degrees, although the stromal component predominated (Fig. 2). The hypocellular stromal-rich areas were formed by myxoid material intermingled with myoepithelial cells with pink cytoplasm and lateralised bland nuclei. The epithelial component consisted of uniform cytologically bland cuboidal cells focally forming ductlike structures (Fig. 3). There was no mitotic activity or nuclear atypia. The diagnosis was pleomorphic adenoma, the hypocellular variant, in all ten resected nodules.

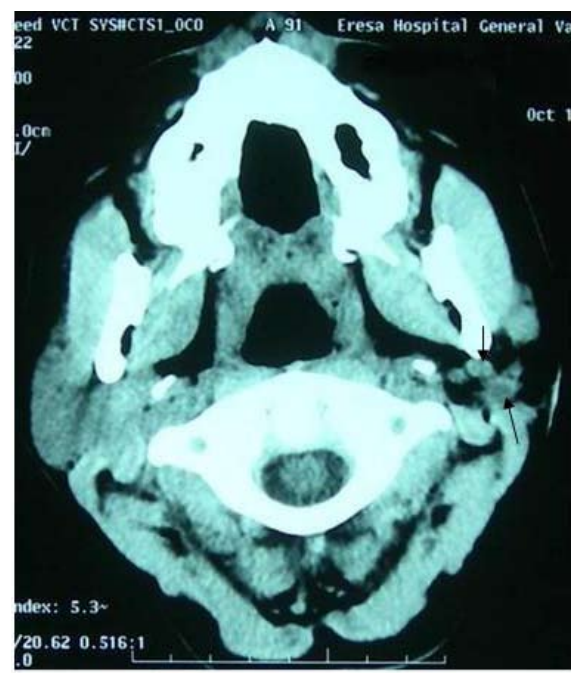

Fig. 1. Cervical computed tomography revealed several small hypodense nodules with fibrous tracts (arrows) in the left parotid region.

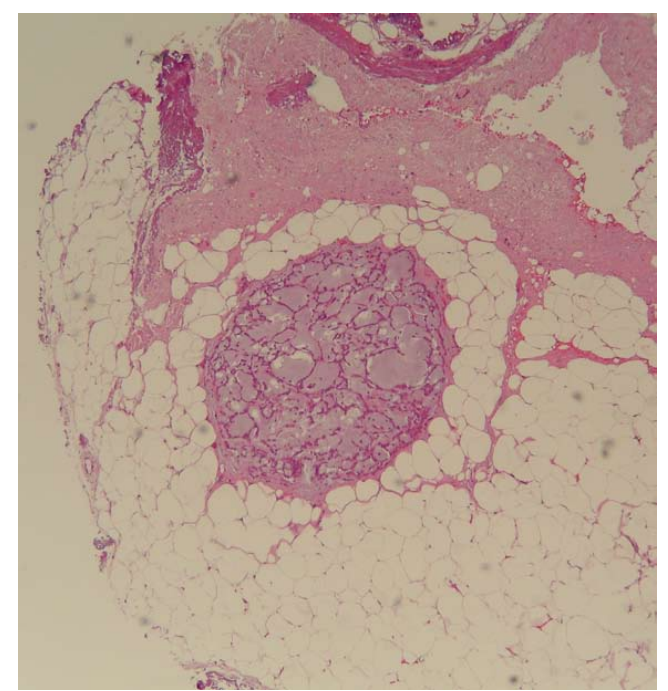

Fig. 2. One of the resected nodes contains a hypocellular component in a myxoid-rich stroma $(\mathrm{H} \& \mathrm{E} \times 20)$.

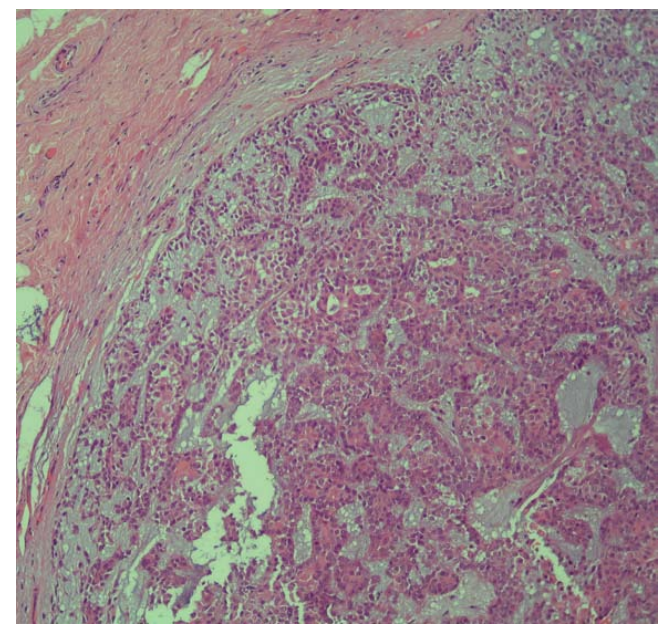

Fig. 3. Focally, the lesion was hypercellular with epithelial cells forming ducts $(\mathrm{H} \& \mathrm{E} \times 100)$.

\section{Discussion}

We describe an example of multifocal parotid pleomorphic adenoma that recurred years after the initial surgical treatment. The two recurrences that we describe occurred at different times. The appearance of several nodules of pleomorphic adenoma was consistent with multifocal, multicentric recurrence.

The knowledge of the inmense variety of cells, architectures and morphological characteristics present in pleomorphic adenoma of the salivary gland is important for a correct diagnosis (5). The multifocal tumour that we present contains a hypocellular component in a myxoidrich stroma. Focally, the lesion was hypercellular with epithelial cells forming ducts.

Parotid pleomorphic adenoma is usually a solitary tumour, but sometimes multifocal tumours can recur after 
surgical excision. Hypocellular pleomorphic adenomas, as in our case, the presence of pseudopodes, and multinodularity are histological factors associated with recurrences and multifocal risk $(6,7)$.

The choice of surgical technique in the treatment of these tumours is very important, in order to reduce the rate of recurrences. Generally, most authors prefer partial or total parotidectomy with facial nerve conservation. This technique is curative for $95 \%$ of the tumours (8). Treatments like tumour enucleation are associated with a high rate of recurrence, as in our case. Some authors defend enucleation treatment because of the moderate rate of recurrence and its low complication rate (9). Nevertheless, most of the authors who defend tumour enucleation hold that the technique should be performed with much care because recurrences are related to the surgeon's skill (10). Other authors (11) report a $45 \%$ recurrence rate for patients treated following tumour enucleation, while total parotidectomy reduces that rate to $2.4 \%$.

The best treatment in children is total parotidectomy with facial nerve preservation. These patients should be monitored for several years because of the possibility of recurrence $(12,13)$. In our case, recurrences occurred 7 and 14 years after the initial surgical treatment.

The treatment of recurrences is complicated and technically difficult because of the fibrosis, adhesions, and changes in anatomic references that increase the risk of facial nerve lesions (14).

\section{Conclusion}

This case shows that enucleation is not a good technique for treating parotid pleomorphic adenoma in childhood and total parotidectomy should be considered as treatment of choice.

\section{References}

1. Luna MA, Batsakis JG, el-Naggar AK. Salivary gland tumors in children. Ann Otol Rhinol Laryngol. 1991;100:869-71.

2. Ellies M, Schaffranietz F, Arglebe C, Laskawi R. Tumors of the salivary glands in childhood and adolescence. J Oral Maxillofac Surg. 2006;64:1049-58.

3. Paris J, Facon F, Chrestian MA, Giovanni A, Zanaret M. [Pleomorphic adenoma of the parotid: histopathological study]. Ann Otolaryngol Chir Cervicofac. 2004;121:161-6.

4. Wittekindt C, Streubel K, Arnold G, Stennert E, Guntinas-Lichius O. Recurrent pleomorphic adenoma of the parotid gland: analysis of 108 consecutive patients. Head Neck. 2007;29:822-8.

5. Ito FA, Jorge J, Vargas PA, Lopes MA. Histopathological findings of pleomorphic adenomas of the salivary glands. Med Oral Patol Oral Cir Bucal. 2009;14:E57-61.

6. Paris J, Facon F, Chrestian MA, Giovanni A, Zanaret M. [Recurrences of pleomorphic adenomas of the parotid: changing attitudes]. Rev Laryngol Otol Rhinol (Bord). 2003;124:229-34.

7. Redaelli de Zinis LO, Piccioni M, Antonelli AR, Nicolai P. Management and prognostic factors of recurrent pleomorphic adenoma of the parotid gland: personal experience and review of the literature. Eur Arch Otorhinolaryngol. 2008;265:447-52.
8. Mendenhall WM, Mendenhall CM, Werning JW, Malyapa RS, Mendenhall NP. Salivary gland pleomorphic adenoma. Am J Clin Oncol. 2008;31:95-9.

9. Smith SL, Komisar A. Limited parotidectomy: the role of extracapsular dissection in parotid gland neoplasms. Laryngoscope. 2007;117:1163-7.

10. Hancock BD. Clinically benign parotid tumours: local dissection as an alternative to superficial parotidectomy in selected cases. Ann R Coll Surg Engl. 1999;81:299-301.

11. Chevalier D, Loche V, Darras JA, Apko-Allavo J, Desaulty A, Piquet JJ. [Reoperation and recurrence of pleomorphic adenoma of the parotid. A propos of 62 cases]. Ann Otolaryngol Chir Cervicofac. 1996;113:56-60.

12. Rodriguez KH, Vargas S, Robson C, Perez-Atayde A, Shamberger R, McGill TJ, et al. Pleomorphic adenoma of the parotid gland in children. Int J Pediatr Otorhinolaryngol. 2007;71:1717-23.

13. Giudice M, Itro A, Marra A, Amodio A. [Pleomorphic adenoma of the parotid gland in childhood]. Minerva Stomatol. 2001;50:20511.

14. Valentini V, Fabiani F, Perugini M, Vetrano S, Iannetti G. Surgical techniques in the treatment of pleomorphic adenoma of the parotid gland: our experience and review of literature. J Craniofac Surg. 2001;12:565-8. 